\title{
4
}

\section{AFFORDABLE HOUSING TRANSITION IN CALGARY}

\author{
Sarah Woodgate, Teresa Goldstein, and Claire Noble
}

\section{Introduction}

The past 20 years have seen a period of change in the Calgary affordable housing sector. Rising housing costs and a rapidly increasing homeless population in the early to mid-2000s drew attention to Calgary's affordable housing issue. In 2008, Calgary's 10 Year Plan to End Homelessness was adopted, with a Housing First approach. In 2013, Calgary's poverty reduction strategy, Enough for All, was adopted, followed by Foundations for Home, Calgary's Corporate Affordable Housing Strategy 2016-2025. The emphasis on partnerships and collaboration saw the formation of Calgary's Community Housing Affordability Collective (CHAC), the collective engine for improving housing affordability through cross-sector collaboration, specific initiatives and project delivery, as well as coordinated sector-wide community-based advocacy for housing affordability-related matters. The affordable housing sector in Calgary has made great strides towards a more collaborative system, has developed many new partnerships, and is now reaping the rewards with improved coordination of service delivery for Calgarians seeking affordable housing programmes and services. Plans are underway to expand this collaboration further, starting with an alignment between CHAC and the Alberta Seniors and Community Housing Association (ASCHA) announced in December 2020.

Public awareness and support for affordable housing remains high. In the Fall 2020 Quality of Life and Citizen Satisfaction Survey, more than half of the residents urged the City to invest more in affordable housing. Almost 95\% of Calgarians indicated that affordable housing for low-income families and individuals is important. Affordable housing has been an ongoing top citizen priority. Furthermore, there is renewed national interest and support by the Government of Canada. Current conditions present an excellent opportunity to advance affordable housing solutions.

This chapter explores the City's strategic directions for affordable housing policy through three primary focus areas:

- Preservation of existing supply: maintain the existing affordable housing currently available through investment, renovation and repair, and programme modernization of existing affordable housing; 
- Scaling-up the non-profit housing sector: moving all municipal levers available to increase the overall housing supply to at minimum achieve the average supply of non-market housing compared with Canada's big cities; and

- Improving the housing system: a people-centric service approach through partnerships to facilitate individual and community well-being for those served.

\section{The Calgary Context}

\section{Housing Supply}

In 2018, The City of Calgary released its report, Housing in Canada's Big Cities, comparing Calgary's housing supply and affordability to Canada's seven largest cities. The key findings from that report were that Calgary's housing supply differs substantially from other Canadian cities. Among the major cities in Canada, Calgary has the highest rate of homeownership and single-family housing, and the lowest supply of purpose-built rental, subsidized housing and co-operative housing. These differences appear to have been influenced by:

- Timing of development: The bulk of housing in Calgary was built during economic 'booms', when demand and incomes were high. Historic market response has been to build an expensive, homogenous supply;

- Income inequality: Calgary has the highest income inequality among the big cities. The proportion of households earning higher incomes is very large, as is the income gap. This has influenced market response, as well as public policy;

- Incentive: There has been a lack of incentive to build some types of housing. This is a result of market demand, but also government funding and policy. Calgary was a relatively small city when government incentives encouraged a wider variety of housing types, and so the City benefitted less from these investments.

The results are a well-served higher-income population and an underserved lower-income population, and while this lower-income population is small, compared to the rest of Calgary, their housing options are limited (The City of Calgary, 2018a).

Overall, the private sector meets the housing needs of over $78 \%$ of Calgary's households. Only $4 \%$ of households earning over $\$ 80,000$ /year spend more than $30 \%$ of their income on shelter (The City of Calgary, 2018a). In terms of policy, the City is focused on maintaining housing affordability with intentional policy effort to support low- and moderate-income households. Calgary has a number of strengths to support affordable housing strategies such as private housing industry talent, a culture of partnership and a philanthropic mindset.

Calgary's non-market housing is provided by 51 organizations operating 12,448 non-market housing units. Overall, only three organizations operate over 500 units, while most organizations (36 of 51) operate fewer than 100 units (The City of Calgary, 2016a). While optimal portfolio size is in the range of 2,000-5,000 homes, however, this is highly dependent on context, geography, and operating models. Few Calgary affordable housing operators approach these numbers. This is why it is important to explore opportunities to scale-up non-market housing to create a more robust and resilient non-profit housing sector. Calgary Housing Company (CHC), a wholly owned subsidiary of The City of Calgary and the largest landlord, provides over 9,000 housing options to approximately 25,000 Calgarians (Calgary Housing Company, 2020). This includes the provision of over half of the non-market units available in Calgary 
(6,811 units) (The City of Calgary, 2016a). The successful and effective management of housing programmes and housing assets is critical to the success of affordable housing.

\section{Housing Need}

In the fall of 2018, The City of Calgary released its 2018 Housing Needs Assessment. The assessment shows that over 80,000 (or roughly one in five) households are in need of affordable housing. ${ }^{1}$ The incidence of need is especially high for the following populations: singles, loneparents, youth, Aboriginals, recent immigrants, and people with disabilities (The City of Calgary, 2018b). The study predicts that over 100,000 Calgary households will be in housing need by 2025 , including over 65,000 renter households. This is due to overall population increase and a relatively constant proportion of households (18\%) experiencing affordability constraints during the last 25 years. The need for affordable housing is growing much faster than the supply, by over 2,000 renter households per year, compared to a supply growth of approximately 300 units per year. Furthermore, Calgary has one of the lowest shares of rental housing stock in urban Canada, as well as the most expensive entry-level housing (The City of Calgary, 2018a). Rents in the lowest quintile (one-fifth of rental units) are among the highest of all Canadian cities (CMHC, 2015).

In Alberta, housing, transportation, and food make up nearly half of the average spending in the household budget. Average annual transportation costs vary greatly throughout Calgary and tend to be lowest in more central areas and those well-served by public transit. This is why it is important to implement policies to protect overall affordability in Calgary, as well as to locate affordable housing in areas that are well-served by transit. Furthermore, an estimated $11 \%$ of Calgary households experience food insecurity, which has been linked to negative health impacts. By providing affordable housing, a household is able to free up more money for nutritious food and other basic necessities. Affordable housing services are developed with consideration to affordable living and community well-being principles to achieve broader objectives including economic prosperity for citizens (The City of Calgary, 2018a).

Research on housing need shows a shortage of affordable housing units in Calgary, as well as a growing shortage forecast over the next ten years. This is why Calgary's strategies place such a high emphasis on protecting and increasing the supply of affordable housing by leveraging all tools available locally to ensure Calgary's readiness for national and provincial housing programmes. Overall affordable housing is seen as a key aspect of Calgary's competitiveness as a foundation for individuals and families to grow.

\section{Foundations for Home: Calgary's Corporate Affordable Housing Strategy}

\section{How the City Focused on a Systems Approach to Help Maintain and Increase Supply, Leverage, Partner, and Improve the Housing System}

Foundations for Home has a vision to increase the supply of affordable housing to the national average of non-market supply of $6 \%$, and to enable the development of a transformed housing system where collaboration between stakeholders drives better outcomes for individuals and community through safe, affordable housing solutions.

In 2016, The City of Calgary adopted Foundations for Home, Calgary's Corporate Affordable Housing Strategy 2016-2025. The strategy includes six strategic objectives, each hinged on bringing partnerships together, refocusing on increasing and preserving Calgary's affordable housing supply, providing expedited planning approvals or leveraging City land. Furthermore, 
two of the objectives focus on improving the housing system (The City of Calgary, 2016b). The strategy is accompanied by an implementation plan that defines initiatives and actions for each objective (The City of Calgary, 2016c). Together, the six objectives address every City lever to meaningfully advance affordable housing in Calgary.

\section{Strategic Direction \#1 - Get the Calgary Community Building}

The City knows that it cannot meet the need for affordable housing alone, which is why the first strategic objective is to get the Calgary community building non-market housing, thereby reducing the proportion of housing offered directly by government over time. The City focused on supporting the scaling-up of non-profit providers in several ways based on feedback on gaps in the housing system. This resulted in a number of initiatives that emerged in the early $2000 \mathrm{~s}$ including momentum created through the 10 Year Plan to End Homelessness (2008-2018) and an ambitious $\$ 120$ million affordable housing fundraising campaign, which involved the private and non-profit sectors' philanthropic mobilization. Nine large housing developments materialized enhancing the competencies of non-profit agencies to act as developers and asset managers of affordable housing on a large scale. Two key gaps where the City could play a role were the cost and time expended to process development approval applications by non-profit providers intending to build affordable housing. To increase the non-market housing supply provided by nonprofit providers, the City has created a new Affordable Housing Coordinator role within the Planning \& Development department, tasked to understand the housing pipeline, to ensure priority service to affordable housing development applications, and to champion these applications through the approval process. The City of Calgary also launched Calgary's Housing Incentive Program (HIP) in 2016 to support non-profit affordable housing developers with pre-development grants of up to $\$ 50,000$ and City fee rebates that typically range from $\$ 100,000$ to $\$ 400,000$ per project. The programme has supported over 2,000 new affordable housing units to date. The non-profit sector has expressed a high level of satisfaction with these programmes, resulting in an average of 177 days for processing of development permits from submission to approval.

The Affordable Housing Tracker was introduced to help track progress towards addressing Calgary's shortfall of affordable housing. The toolset includes series of reports on affordable housing development in Calgary since January 2016. It captures new construction supported by the City, including active and completed developments, and includes preliminary inquiries and pre-applications. Since 2016, 1,171 City-supported new affordable housing units have been completed. There are an additional 1,806 units currently under development (The City of Calgary, 2020). This represents a progress of $20 \%$ against the 15,000 non-market units targeted in the Affordable Housing Strategy. Even with additional funding, as outlined in the COVID-19 Community Affordable Housing Advocacy Plan, we anticipate reaching a maximum of 6,651 units by 2025 , or $44 \%$ of the 15,000 unit goal. The large majority $(78 \%)$ of units that were completed or under development came from the non-profit sector.

December 2020 marked another milestone in scaling-up the non-profit housing sector in Calgary. The Government of Canada announced \$24.6 million in Rapid Housing Initiative funding for 176 new units of affordable housing in Calgary through a new innovative municipal bilateral stream. The new units will be delivered through three projects: a hotel conversion into a seniors' resident (by Silvera for Seniors), new modular homes for women and children fleeing domestic violence (by Horizon Housing), and new homes for Indigenous people as part of a rehabilitation of an old building (by HomeSpace Society). There is additional funding available under the Rapid Housing Initiative in 2021 that could help further add affordable housing supply in Calgary for citizens experiencing or at-risk of homelessness. With the Government of 
Canada announcement in 2020 to eliminate chronic homelessness, there is potential for future significant additional investment to support the scaling-up of non-profit housing (The Government of Canada, 2020). While there is much work that needs to be done to close the supply gap for affordable housing in Calgary, the newly established programmes offered by the City in partnerships with housing providers positively position the City to benefit from federal affordable housing programmes. One limitation to increase the affordable housing supply is the gap of available operating dollars for supportive housing and rent supplement programmes to expand housing options for the lowest-income households.

\section{Strategic Direction \#2 - Leverage City Land}

In 2015, non-profit housing providers identified access to land at discounted value as a key barrier towards increasing affordable housing supply. Another challenge for non-profits was navigating timing and criteria for federal, provincial, and municipal housing programmes. To address these barriers, the second strategic direction leverages City land to support and scale-up non-market housing providers, allowing them to build their assets, scale-up their housing portfolios, and increase their financial sustainability while also accessing federal and provincial housing programmes. The initial target approved by City Council was to sell ten parcels of City-owned land below the market value for affordable housing by 2018 through a pilot programme. Successful applicants automatically qualified for grant funding through the City's HIP and Canada Mortgage and Housing Corporation's (CMHC) SEED Funding programme. The pilot resulted in the sale of six development sites, generating up to 165 new affordable homes constructed and occupied in about two years. The City invested $\$ 6.4$ million in land value, which brought in more than $\$ 30$ million in federal, philanthropic, and private sectors funding for the projects. This initiative provided a variety of new affordable housing choices meeting gaps in housing supply, including home ownership for families through Habitat for Humanity, tiny modular housing for veterans by Homes for Heroes in partnership with Atco, and permanent supportive housing for singles provided by Home Space in partnership with private sector builders.

The success of the pilot project resulted in a Council-approved Non-Market Housing Land Disposition Policy and ongoing City land programme committing to release up to ten parcels of developable land every two years (The City of Calgary, 2019). Subsequently, five City-owned development sites were offered to non-profits at below-market value in January 2020. New to the programme in 2020, successful applicants were eligible to receive additional funding under CMHC's National Housing Co-Investment Fund through an expanded City/federal programme coordination pilot.

Land sale is currently the preferred method over land leases to scale-up the non-profit financial capacity and asset-building opportunities and provide the non-profit with greater accountability over the condition of the building and the land asset to achieve strategic housing objectives. To ensure that the public benefit is met over a long term, the City is entering into housing agreements with the successful non-profits, a new provision under the Alberta Municipal Government Act. This programme will support affordable housing providers to develop institutional capacity of the sector as well as result in increased supply.

\section{Strategic Direction \#3 - Design and Build New City Units}

The third strategic direction is the design and build of new City-owned affordable housing units. The City's short-term target to open 270 units in 2017 and 2018 represents a near-doubling of the number built in previous years and accounted for all of the remaining capital dollars in 

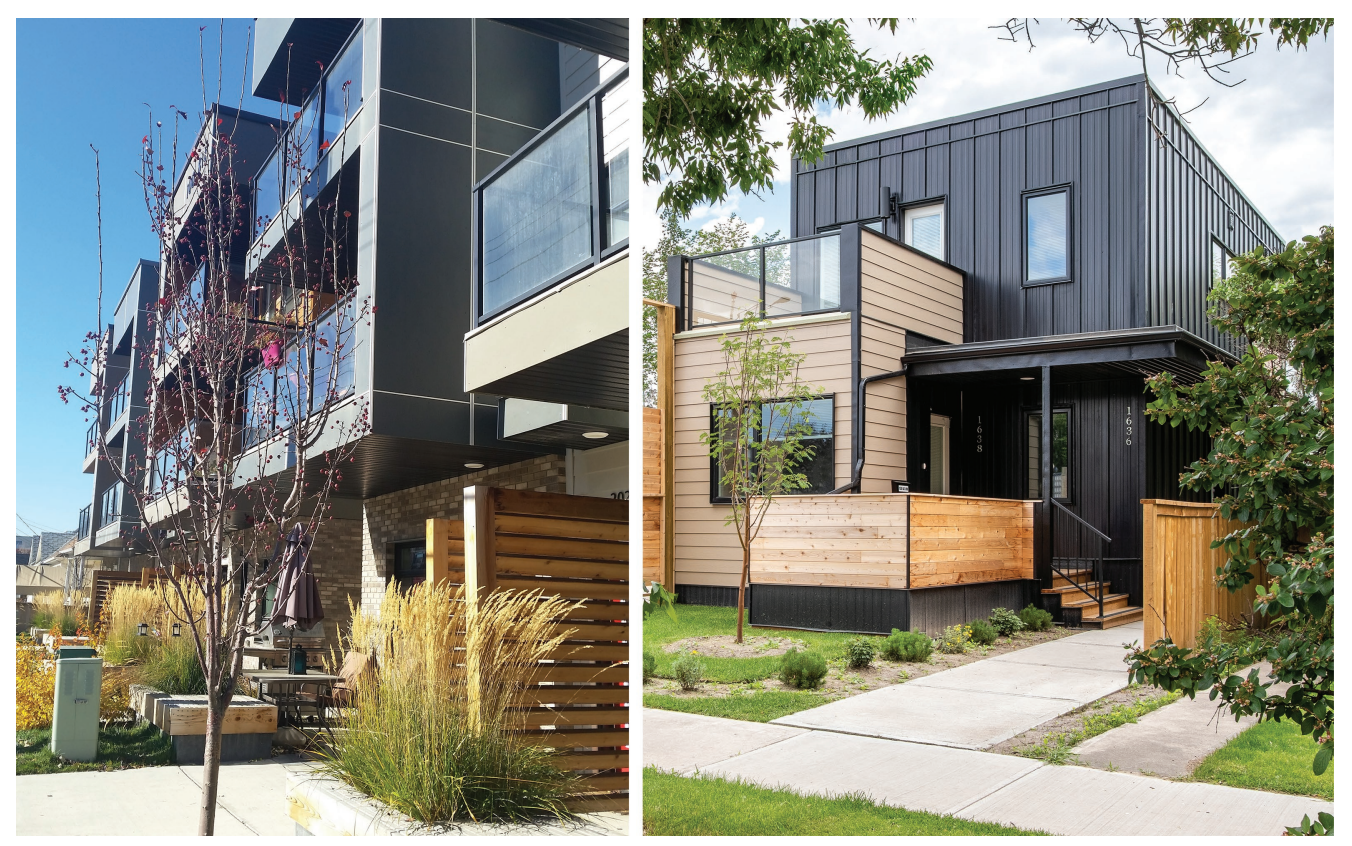

FIGURE 4.1 Affordable Housing in Wildwood and Rosedale.

Source: (C) Sasha Tsenkova.

the City's affordable housing budget. This strategic direction is critical given Calgary's shortage of affordable housing, and complements the new affordable housing built by the non-profit sector. Wildwood is an example of a recently completed City-initiated development (see Figure 4.1).

The City's previous affordable housing developments were often done on large rectangular lots. Recent solutions utilize other types of lots, such as remnant parcels, transit-oriented development sites, and restoration and reuse of heritage properties. The City piloted 16 narrow units on eight sites in Calgary created through a City-wide redevelopment initiative along Highway 1. These Rosedale homes shown in Figure 4.1 are now complete and occupied.

The City is also developing 62 units in Bridlewood community. The energy-efficient performance of these homes is $41 \%$ better than standard in the 2015 National Energy Code for Buildings. Water efficiency meets LEED V4 requirements. Five units have photovoltaic solar cells linked to the individual electrical metre system to support the tenants in their bills. One of the seven town homes is built to higher energy efficiency standards allowing for the comparison of simple return on investment through lower operating costs in relation to the increased construction costs. In addition, the City is developing 145 units in the Rundle community and completing the concept design of 200 units in Southview community along International Avenue.

The City is also looking for opportunities to both retain existing units and incorporate new units along the future green line of the light rail transit (LRT) system and to integrate affordable housing with other civic uses, such as fire halls, libraries, and recreation centres. The combination of mixed used facilities optimizes City land holdings and creates opportunities for vibrant, dynamic, and successful living environments for the future residents with access to quality programmes, services, and volunteer opportunities. Furthermore, the City is moving towards creating 1-, 2-, and 3-bedroom accessible units to accommodate both individuals and families with accessibility needs. 


\section{Strategic Direction \#4 - Regenerate City-owned Properties}

The strategic direction is intended to protect the existing affordable housing supply, which is important given Calgary's large supply shortage. The average age of affordable housing provided by CHC is over 30 years and in need of major repairs. Since 2017, hundreds of existing homes have undergone critical major repair and condition assessment. The majority of existing Cityand CHC-owned affordable housing properties can be fully retrofitted at a fraction of the cost of investing in new units. In the case of a redevelopment in Bankview, the investment prolonged the building's life by 25 years, while improving and updating the building to meet the current demographics and building condition standards. The full repair and renovation of Bankview affordable housing was $\$ 50,000 /$ unit. The project also transitioned units from full market rental housing (rent-geared-to-income) to mixed-income rental housing offering an increased supply of homes to low- and moderate-income households without the requirement for government subsidy.

Undertaking strategic redevelopments has allowed the City to stretch capital funding even further to optimize land and real estate options. In 2021, a rental housing property with 75 units in the community of Rundle is being closed due to the site conditions. Plans are underway for a new mixed market development to proceed on the site, with up to 145 new homes further expanding housing options. The decision to close a property is significant and impacts residents. $\mathrm{CHC}$ has been actively supporting tenants to transition to alternate housing. These supports include linking tenants to other available housing providers and offering discounted rents for 18 months and partnering with a non-profit provider who is helping residents save up to $\$ 7,000$ to support their housing transition. Five households are participating in an affordable homeownership programme for acquiring their own home. The current residents are also involved in the redesign process for the new development.

\section{Strategic Direction \#5 - Strengthen Intergovernmental Partnerships}

This strategic direction reflects the philosophy that affordable housing is a shared responsibility of all orders of government, as well as the value that the City places on collaboration. The City's Non-Profit Land Transfer Program is an example of where collaboration has occurred between the City and the federal government. Successful recipients of the programme also receive funding from the City's HIP and a dedicated addition from the CMHC's SEED funding programme, marking a meaningful collaboration between two levels of government. CMHC reviewed the applications concurrently to analyse them for SEED Funding eligibility. This is the first-of-its kind collaboration between The City of Calgary and the federal government to expedite the release of land and funding for affordable housing development through a streamlined application process for non-profit providers. This collaboration allowed for a stacking of programmes between governments to respond to local need, have one application point for non-profit providers, and reduce the application review time. The coordination of government programmes results in more streamlined process for government officials administering the programme and has supported efficient housing delivery timelines for housing providers. By leveraging the unique roles of each government through coordinated programme delivery, there is significant opportunity to more rapidly deliver affordable housing solutions and to align the different levels of government. This approach for coordinated affordable housing application review between local, provincial, and federal governments can be a model for future intergovernmental partnerships (Box 4.1).

The City is also working closely with the Provincial Government through the City's participation in the Big City Housing collaborative to improve the quality of life of Albertans in need of affordable housing. In July 2020, the City and the Province of Alberta signed a four-year, $\$ 34-$ million operating funding agreement governing the delivery of the City's Community 


\section{BOX 4.1: HOMESPACE-36 STREET SE}

HomeSpace Society was selected as the successful organization to purchase a parcel of land in the City's Southeast through the City's non-profit land transfer programme. The programme offered City land at below-book value to eligible non-market housing providers with the goal of helping to scale-up the housing sector and increase the supply of non-market units in the City. HomeSpace's proposed project will provide 38 studio units of permanent supported living in the southeast community of Forest Lawn. The units range in size from 250 to 300 square feet, and the building also includes common spaces such as a communal kitchen to serve as a gathering area for the residents.

The City supported the project by placing all related development applications on prioritized accelerated timelines. The complete approval timeline from submission of the landuse re-designation application to the approval of the development permit application was 105 days. The project also received support from the City's HIP including a $\$ 50,000$ grant to cover pre-development expenses and an estimated additional $\$ 92,000$ to cover City development application fees and offsite levy costs. CMHC partnered with the City to provide dedicated funding towards supporting the feasibility and start-up costs associated with the project, helping it as it proceeds forward through development.

Housing Portfolio (CHP) of 1,048 units. This new agreement, to maintain the supply of existing housing through a mixed-rent model, comes into effect in 2021. This agreement is a joint affordable housing commitment and partnership between the City and the Province that helps ensure that affordable housing in Calgary is adequately funded and maintained to meet health and safety standards and to provide opportunities to low-income Calgarians.

The signing of this progressive funding agreement with the Province will enable the transition of all City-owned housing to a mixed-rent model. Mixed-rent housing allows households of mixed financial means to live as neighbours. The renewed operating agreement, which will be implemented through a gradual transition towards mixed-rent housing, will enable more operating flexibility with simplified regulation, serve a diversity of households that fall under the income thresholds, and reduce government subsidy over time. This initiative, combined with additional federal and provincial investment in new affordable housing units, will support a more sustainable affordable housing supply in the long term that requires less government subsidy over time.

\section{Strategic Direction \#6 - Improve the Housing System}

The final strategic direction is to improve the housing system through research, programmes, and partnership to create better outcomes for people. This reflects the values of becoming people-centred as well as evidence-based. It also reflects the recognition of the complexity of the housing system, and that collaboration is necessary for the most effective delivery of services to people. The Foundation for Home Community Development Plan, One Window Project, and the City's participation in CHAC fall under this strategic direction.

In 2016, the City launched The Foundation for Home Community Development Program ("The Home Program"). This micro grant programme includes a number of projects aimed at meeting two key outcomes for people living in affordable housing: to improve resident self-sufficiency and enhance community well-being. RentSmart is an adult education programme developed 
by Ready to Rent BC. It aims at empowering renters, who understand their rights and responsibilities with a focus on stable and successful tenancies. The curriculum covers a number of topics including the understanding the Residential Tenancies Act, managing finances, and taking care of the home. So far, The Home Program has supported over eight cohorts of CHC tenants, more than 68 tenants in total, to graduate from RentSmart. It has also supported over 12 nonprofit organization to attend a trainer course to deliver RentSmart to their own tenants looking to move from supportive care and shelters into independent living.

The One Window Project is another example of efforts to improve the housing system. It aims at creating a coordinated intake process across 60 independent organizations that operate non-market housing in Calgary. The goal is to improve the application experience from a client perspective, so that more people can be efficiently and successfully housed. CHAC has expressed the desire to extend the One Window solution for Province-wide application. In December 2020, The Government of Alberta accepted the Alberta Affordable Housing Review Panel recommendation \#14 to "Work with housing operators to develop a centralized housing portal to manage waiting lists, including vacancies, and develop standardized application forms for the community housing and seniors lodge programs" (SHS Consulting, 2020).

\section{Affordable Housing Service Delivery by Calgary Housing Company and The City of Calgary}

\section{How the City's Housing Policy Has Refocused on Maintaining Existing Affordable Housing through Investment, Renovation, and Programme Modernization of Existing Social Housing Projects}

In 2015, Calgary City Council identified a need to reorganize how housing services were delivered. The change included bringing the City-owned not-for-profit corporation - $\mathrm{CHC}-$ and the City affordable housing functions together as two legal entities under one service called Calgary

\section{BOX 4.2: PARTNERSHIP WITH LEFTOVERSYYC}

The City's partnership with LeftoversYYC is an example of an activity to increase affordable housing residents' access to well-being services and activities (Leftovers Calgary Foundation, 2018). The Community Mobile Food Market is a community-driven grocery store on wheels that increases the availability of healthy and affordable foods in underserved neighbourhoods of Calgary. The goals of the Community Mobile Food Market are to:

- Build upon existing community assets to strengthen community;

- Highlight other organizations in the community as opportunities to strength partnerships/ leverage existing services;

- Increase access to affordable, healthy products.

The market is open to all regardless of financial income with a goal to bring healthy food to the door at a reduced cost, and, as a result, reduce potential barriers individuals may face. The work of community organizations to leverage partnerships and pilot innovative programmes such as LeftoversYYC has worked to increase access to residents' well-being services, creating stronger ties within between neighbourhoods and increasing in volunteerism. 
Housing. The idea behind the reorganization was to maintain the existing affordable housing supply, work collectively with both the creation and operation of new and regenerated affordable housing, as well as modernize existing programs and services. Calgary Housing is embedded within the Community Service department, which includes fire, parks, recreation, emergency management, neighbourhoods, and community standard (911) services. This change has enabled the frontline housing services staff to coordinate service needs with other municipal functions, thereby streamlining processes and focusing on citizen-centred service delivery. Many of the initiatives described below target CHC's top challenges: insufficient and uncertain funding, management of third-party assets, and incomplete operating agreements with government partners.

\section{Asset Management}

Calgary Housing Company's Strategic Asset Management Program supports long-term planning of its assets. $\mathrm{CHC}$ is now providing asset management service to the City for housing that is in their ownership and has begun investing in the upgrading of City-owned social housing units including the upgrading of units in community housing to a new base standard. There is a cultural shift from an emphasis on modest standard to an emphasis on competitive rental products to shift to a mixed market portfolio approach. A focus on asset management is critical given that the condition of third-party assets and the inadequate reserve funds are among CHC's top challenges. The Municipal Stimulus Program (MSP) will fund \$9.3 million in major repairs in 2021.

\section{Sustainability}

CHC's Sustainability Program uses operational data and financial forecasting to identify recommendations and innovations to address the impact of the expiry of federal and provincial operating agreements to $\mathrm{CHC}$. This programme is informed by best practices to ensure financial sustainability and viability for $\mathrm{CHC}$. The programme includes the optimization of assets as well as the provision of data and information to inform advocacy and future decision-making.

The sustainability programme also supports deeper analysis of the viability of mixed market portfolios offering a mix of near-market rent and deep subsidy without operating subsidies. To date, applying a mixed market portfolio has provided over $\$ 25$ million in returns to the City in ten years, which is reinvestment in new housing and City programmes. The CHC also has programmes in place for temporary relief of rent for near-market tenants who may need additional social supports and who face financial challenges, which is a unique role compared to a traditional landlord.

\section{Mixed Market Model}

$\mathrm{CHC}$ is transitioning to a mixed market rental model as it adds new buildings to its portfolio. This type of portfolio offers several benefits in that it is more financially sustainable, socially integrates low-income households throughout the portfolio, and has the potential to support and accommodate households as their circumstances and needs change. It is both sustainable and people-focused.

\section{Portfolio Management Approach}

To leverage the implementation of sound asset management, sustainability, and mixed market principles, a portfolio management approach has been implemented which involves cross-corporate 
integration of information on property condition, operation, and tenancy to optimize the provision of safe affordable housing into the future. Portfolio management introduces the alignment of capital investments, maintenance, and tenancy with the intention of delivering housing that is financially sustainable, supports defined programme requirements, and remains operationally viable. The intent of portfolio management is to monitor property performance, strategically invest in existing properties when appropriate, and make the recommendation to discontinue property operation when it can no longer viably sustain required operational and financial requirements. An example of the implementation of this portfolio management approach is the assessment and decision to redevelop the Rundle property described above. An assessment of the current property based on property condition, forecasted investment requirements, potential for increased unit intensity, and property location was conducted. This resulted in a decision that the current infrastructure on the property was no longer viable, but the land provided excellent proximity to amenities for families and allowed an increase in the number of units. A recommendation was made to demolish the current property, reallocate tenants, and commission a preliminary design to determine the need for new funding.

\section{A People-Focused Approach}

$\mathrm{CHC}$ has transitioned from a focus on primarily bricks and mortar to a more people-focused approach. This reflects a gradual philosophical shift that is related to the Housing First concept. CHC believes that tenant perspectives should play a significant role in shaping priorities for tenant service. In 2017, the tenant advisory group (TAG) was formed, and the first Tenant Satisfaction Survey was administered. Tenant engagement has also been utilized as a tool to inform the future state for Calgary Housing's Transformation. It will be important to ensure that such engagement continues and informs decision-making and continuous improvement for all facets of service delivery. Together the goal is to provide services that support tenants to achieve individual and community well-being towards their highest potential, including opportunities for civic engagement.

Partnerships and coordinated services between providers is key to delivering this peoplefocused approach. An example is CHC's Opportunities for Homeownership Program which brings five local agencies together to educate tenants on their options for home ownership. As well, CHC has partnered with Habitat for Humanity to identify new homes specifically for tenants and has seen over 100 households per year transition to affordable home ownership since 2016. Another example is Bridging the Gap, a CHC programme aimed at supporting people in their transitions from supportive housing to independent housing. This transition programme has freed up homes for new Housing First clients with successful transitions for the graduates into independent living.

\section{Conclusion}

Over the past 20 years, Calgary has seen a period of significant change in the affordable housing sector. Research on housing need highlights the continued pressing need to increase the affordable housing supply and to scale-up non-profit affordable housing providers. The change to bring $\mathrm{CHC}$ and the City affordable housing functions together has created a number of opportunities for increased collaboration and aligned service delivery. This, combined with philosophical shifts and market challenges, has led to the advancement of a number of initiatives around asset management, sustainability, and a more people-focused approach. In the future, $\mathrm{CHC}$ will emphasize programmes that are flexible, tied to the person, and empowering. The 
City is on track to meet the targets and commitments laid out in Foundations for Home: Calgary's Corporate Affordable Housing Strategy. Through the creation of strong partnerships across the sector and within CHAC, and plans to expand this collaboration further, Calgary is well underway to realize its vision for affordable housing.

Across all activities within the Calgary affordable housing sector, the key to success has been collaboration: within The City of Calgary itself, with other orders of government, with housing providers, with community organizations, and with affordable housing residents. It takes a coordinated effort from everyone to deliver safe, appropriate, inclusive housing options for the entire community. A strong and healthy housing system is one that is flexible to respond to market and political changes, and it is dependent on long-term political support. Working together, the capacity exists to establish programmes and policies that will create success into the future, remove barriers, generate creative solutions, and drive systemic change to improve the lives of low- and moderate-income Calgarians.

\section{Acknowledgements}

The authors acknowledge the contribution of the following experts: Cheryl Selinger, Leanne Hall, Medhat Hanna, Raja Brahmakshatriya, Tim Ward, Meaghan Bell, Kendra Ramdanny, Katherine Plotnick, Susan Sanderson, Katie Gusa, Nina Nagy - The City of Calgary; Community Housing Affordability Collective Steering Committee members 2018; Calgary Housing Corporate Management Team - Aminda Galappaththi, Maureen Swanson, Greg Wilkes, Meaghan Bell, John Veenstra, Bruce Sinclair, Bo Jiang, Brandi Kapell, Jana Tchinkova; Calgary Housing Company Board of Directors

\section{Note}

1 The City of Calgary defines a household as in need of affordable housing if they are currently spending more than $30 \%$ of income on shelter and they earn no more than $65 \%$ of the Calgary median income.

\section{References}

Calgary Housing Company. (2020). Calgary Housing Company Annual Report 2019. http://calgary housingcompany.org/wp-content/uploads/2018-Annual-Report_Final_opt.pdf, accessed December 18,2020

Canada Mortgage and Housing Corporation. (2016). Purpose-Built Rental Apartments with Rents in the Lowest Rent Quintile. http://publications.gc.ca/collections/collection_2017/schl-cmhc/nh12268/NH12-268-2016-2-eng.pdf, accessed December 18, 2020

Leftovers Calgary Foundation. (2018). https://yyc.rescuefood.ca/cmm-project, accessed August 31, 2018

SHS Consulting. (2020). Final Report of the Alberta Affordable Housing Review Panel. https://open. alberta.ca/publications/final-report-of-alberta-affordable-housing-review-panel, accessed January 4, 2021

The City of Calgary. (2016a). Housing in Calgary: An Inventory of Housing Supply, 2015/2016. www.calgary.ca/content/dam/www/cs/olsh/documents/affordable-housing/housing-in-calgaryinventory-housing-supply.pdf, accessed December 18, 2020

The City of Calgary. (2016b). Foundations for Home: Calgary's Corporate Affordable Housing Strategy 2016-2015. www.calgary.ca/cs/olsh/affordable-housing/affordable-housing.html, accessed December 18,2020

The City of Calgary (2016c). Foundations for Home: Calgary's Corporate Affordable Housing Strategy Implementation Plan. www.calgary.ca/cs/olsh/affordable-housing/affordable-housing.html, accessed December 18, 2020 
The City of Calgary. (2018a). Housing in Canada's Big Cities. www.calgary.ca/CS/OLSH/Documents/ Affordable-housing/Housing-in-Canadas-Big-Cities.pdf, accessed December 18, 2020

The City of Calgary. (2018b). Housing Needs Assessment 2018. www.calgary.ca/content/dam/www/ cs/olsh/documents/affordable-housing/affordable-housing-needs-assessment.pdf, accessed December 18,2020

The City of Calgary. (2019). Non-Market Housing Land Disposition Policy. www.calgary.ca/content/ $\mathrm{dam} / \mathrm{www} / \mathrm{ca} /$ city-clerks/documents/council-policy-library/non-market-housing-land-dispositionpolicy-2019.pdf, accessed January 5, 2021

The City of Calgary. (2020). Calgary Needs More Affordable Housing. www.calgary.ca/cs/olsh/affordable-housing/community-affordable-housing-advocacy-plan-community-plan.html? redirect=/communityplan, accessed January 4, 2021

The Government of Canada. (2020). A Stronger and More Resilient Canada: A Speech from the Throne to Open the Second Session of the Forty-Third Parliament of Canada. www.canada.ca/content/dam/pco-bcp/documents/pm/SFT_2020_EN_WEB.pdf, accessed January 5, 2021 